\title{
A new plant carbon isotopic framework for identifying forest and grassland transitions over the last 30 million years
}

\author{
KRISTEN M. SCHLANSER ${ }^{1 *}$, AARON F. DIEFENDORF ${ }^{2}$, \\ KEVIN E. MUELLER ${ }^{3}$ \\ ${ }^{1,2}$ University of Cincinnati, Cincinnati, OH 45221, USA \\ (*correspondance: kschlans@gmail.com) \\ ${ }^{3}$ Cleveland State University, Cleveland, OH 44115, USA
}

As vegetation responds to climate change at rates and magnitudes not observed in millions of years, it becomes increasingly necessary to use the paleorecord to better understand how vegetation has adapted to past warm periods. In the absence of plant fossils, preserved plant-derived organic matter and specific compounds (e.g., leaf waxes) can be used to reconstruct paleovegetation. Terrestrial plants almost exclusively synthesize carbon using the $\mathrm{C}_{3}$ or $\mathrm{C}_{4}$ photosynthetic pathways, which result in unique carbon isotopic compositions in leaves $\left(\delta^{13} \mathrm{C}_{\text {leaf }}\right)$. Many studies rely on globally averaged $\mathrm{C}_{3}$ and $\mathrm{C}_{4} \delta^{13} \mathrm{Cleaf}_{\text {lea }}$ end member values and simple linear mixing models to track transitions from forests to $\mathrm{C}_{3}$ grasslands and the emergence of $\mathrm{C}_{4}$ grasses. However, within a biome, the distribution of $\delta^{13} \mathrm{C}_{\text {leaf }}$ values are complex and often poorly resolved due to variations in the vegetation assemblage of that biome. This poses a challenge

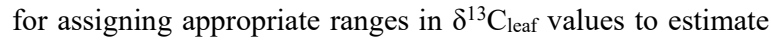
confidence intervals in paleovegetation reconstructions. Selecting appropriate end-member values based on mean global $\delta^{13} \mathrm{C}_{\text {leaf }}$ values versus biome or climate-specific $\delta^{13} \mathrm{C}_{\text {leaf }}$ values will also influence interpretations for the presence and abundances of $\mathrm{C}_{3}$ and $\mathrm{C}_{4}$ vegetation in the geologic record.

Here we provide a new carbon isotopic framework for investigating how $\mathrm{C}_{3}$ and $\mathrm{C}_{4}$ vegetation assemblages change across landscapes and through time. We compiled modern published data sets of $\delta^{13} C_{\text {leaf }}$ values based on biome, photosynthetic pathway, growth form (i.e., trees, shrubs, grasses, forbs), plant function type (evergreen versus deciduous), and various climatic parameters (i.e., mean annual precipitation, mean annual temperature). From this compilation, we provide ranges of $\mathrm{C}_{3}$ and $\mathrm{C}_{4} \delta^{13} \mathrm{C}_{\text {leaf }}$ values as a function of biome and these other climatic parameters. The resulting $\delta^{13} \mathrm{C}_{\text {leaf }}$ distributions help to isotopically define closed-canopy forests, savannas, and treeless grasslands in modern biomes and provide a reference for future paleovegetation reconstruction studies to better approximate the range of uncertainty in mixing models and to select biome-specific end member values for investigating how landscapes evolve through space and time. 